\title{
Локальные термоэлектрические эффекты в широкозонных полупроводниках
}

\author{
(C) С.В. Ордин, Ю.В. Жиляев, В.В. Зеленин, В.Н. Пантелеев \\ Физико-технический институт им. А.Ф. Иоффре Российской академии наук, \\ 194021 Санкт Петербург, Россия \\ E-mail: stas_ordin@mail.ru
}

(Получена 27 декабря 2016 г. Принята к печати 12 января 2017 г.)

Получено экспериментальное подтверждение возникновения в структурах на базе широкозонных полупроводников локальных термоэдс, обнаруженных ранее на кремниевых $p-n$-переходах. Были исследованы вольт-амперные и частотные характеристики асимметричного потенциального барьера на границе $\mathrm{GaN} / \mathrm{Mg}$ и $p-i-n$-структуры на базе GaAs. Показано, что вклад локальных термоэдс и в широкозонных полупроводниках определяет как особенности вольт-амперных характеристик, так и особенности частотных вольт-ваттных характеристик, в частности гауссов резонанс. При учете и использовании локальных термоэдс возможно как кардинальное повышение кпд термоэлектрического преобразования, так и улучшение рабочих параметров элементов микроэлектроники.

DOI: 10.21883/FTP.2017.07.44643.29

Термоэлектричество [1-3], вслед за микроэлектроникой, шагнуло в область широкозонных полупроводников. Но если диффузные слабые эффекты Зеебека и Пельтье электроникой справедливо выбрасывались из рассмотрения, то обнаруженные локальные термоэлектрические эффекты сами существенно влияют на работу устройств микроэлектроники [4]. Локальные термоэдс определяются $E_{g}[5,6]$ и задача повышения кпд термоэлектрических устройств [7-10] пересеклась с задачей повышения эффективности устройств микроэлектроники. При этом, как измерения на низких частотах модуляции [11], так и импульсные измерения [12] кремниевых $p-n$-переходов, показали, что сигналы на относительно небольшой

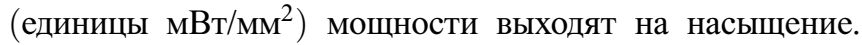
Таким образом, для работы при больших градиентах температуры и кардинального повышения кпд термоэлектрического преобразования нужно переходить на широкозонные полупроводники и создавать многослойные переходы (в популярном изложении см. [13]).

Метод газовой эпитаксии с поэлементным вводом ингредиентов в реактор с продувкой между вводом ростовых элементов (режим атомно-слоевой эпитаксии) позволяет контролировать рост с точностью до монослоя и выращивать гетероструктуры на базе широкозонных материалов $\mathrm{GaN}-\mathrm{AlN}$ на различных подложках $[14,15]$. Был исследован выращенный этим методом образец $\mathrm{GaN}$ толщиной 5 микрон на затворе толщиной меньше 0.2 мкм AlN, на подложке $\mathrm{Al}_{2} \mathrm{O}_{3}$ толщиной около 500 мкм. Тесный тепловой контакт $\mathrm{Al}_{2} \mathrm{O}_{3}$ подложки с полированным медным радиатором и пленки $\mathrm{GaN}$ с электрическими медными контакты обеспечивала InGaэвтектика (рис. 1,a).

Установлено, что эдс на контакте металл/GaN $\alpha_{c}$, так же как и на контакте металл/Si, превосходила вклад объемной интегральной эдс $\alpha_{v}$. При этом малая объемная термоэдс дает знак носителей тока, противоположный холловскому, что указывает на существование в образце как дырок, так и электронов. Полуметаллический характер использованного образца $\mathrm{GaN}$ определял малый потенциальный барьер на его границе с металлом и соответственно малые локальные термоэдс при тесном контакте $\mathrm{GaN}$ с магниевым электродом (рис. 2, a). Однако величины генерируемых ими токов было достаточно, чтобы модулировать ток в пленке $\mathrm{GaN}$ (рис. 2,b) и тем самым реализовать трансформатор сопротивления Лосева на GaN.

На тесном контакте GaN/Mg был создан также термотранзистор Лосева, в котором модуляция тока в пленке $\mathrm{GaN}$ осуществлялась локальными термоэдс, возникающими при нагреве пленки $\mathrm{GaN}$ относительно магниевого радиатора, падающим на нее сквозь прозрачную подложку из $\mathrm{Al}_{2} \mathrm{O}_{3}$ излучением (рис. 3,a). При этом в интервале частот 9 Гц-150кГц регистрировалась амплитуда модуляции входного напряжения при различных входных токах смещения (рис. $3, b$ ).

Возможность регистрации больших локальных термоэдс обеспечивал асимметричный потенциальный барьер на тесном контакте GaN/Mg. При этом амплитуда модуляции входного напряжения на магниевом контакте на порядки превосходила чисто болометрический эффект на контактах пленки $\mathrm{GaN}$ (рис. $1, b$ ) при облучении ее между контактами. Но полуметаллический характер образцов $\mathrm{GaN}$ ограничивал возможность регистрации локальных термоэдс на границе с $\mathrm{Mg}$ без входного тока. При этом и для их регистрации без тока во входной цепи термотранзистора, и для уменьшения эффекта закорачивания сопротивления пленки $\mathrm{GaN}$ малым сопротивлением массивного металлического электрода/радиатора требовался микронный зазор на контакте $\mathrm{Mg}$ с $\mathrm{GaN}$ и дополнительный контакт на пленке $\mathrm{GaN}$, со стороны подложки. Использование зазора позволило в принципе регистрировать выходные, усиленные сигналы 


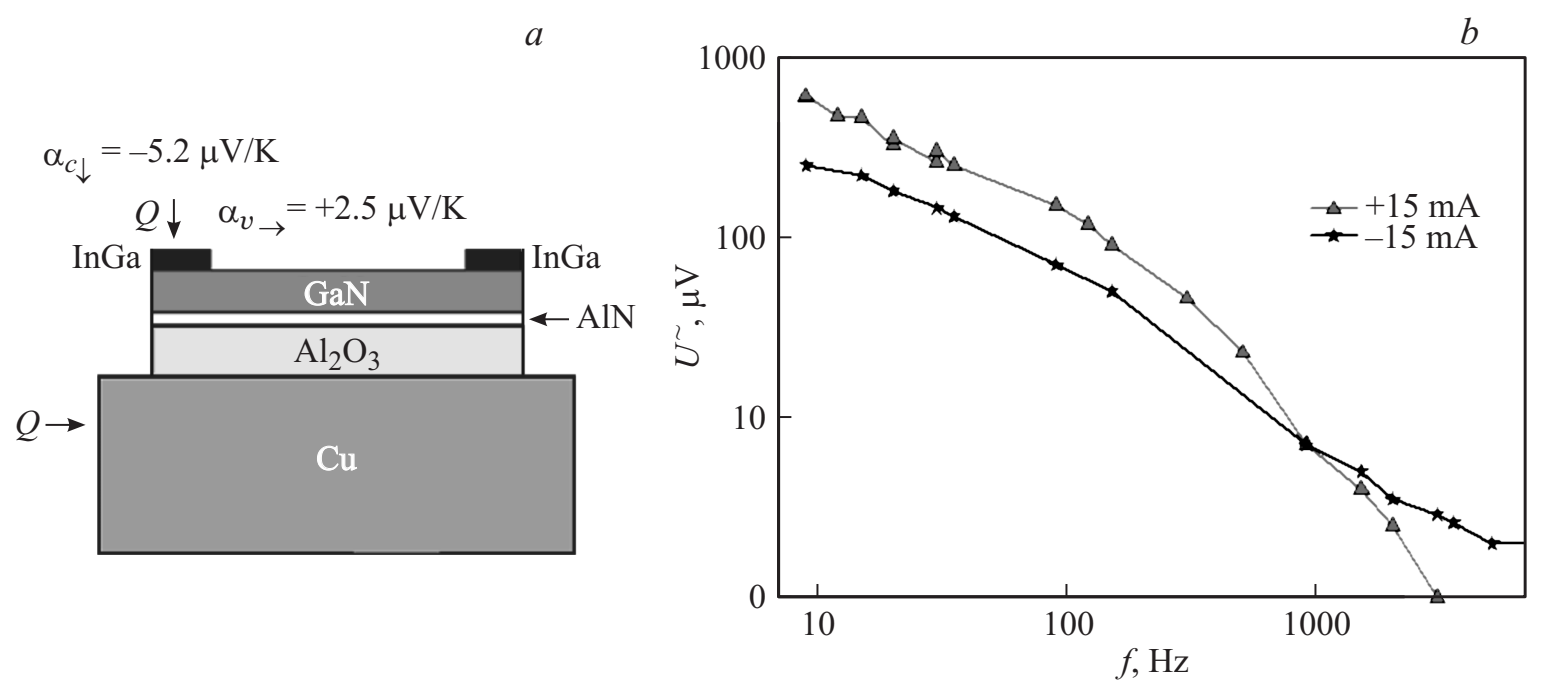

Рис. 1. $a-$ структура образца $\mathrm{GaN} / \mathrm{AlN} / \mathrm{Al}_{2} \mathrm{O}_{3}$ без $\mathrm{Mg}$-контакта. $b$ - зависимость амплитуды модуляции входного напряжения от частоты модуляции тока. Термоэдс контакта $\alpha_{c}$ и объема $\alpha_{v} \mathrm{GaN}$, измеренные при указанных на рисунке направлениях теплового потока $Q$.
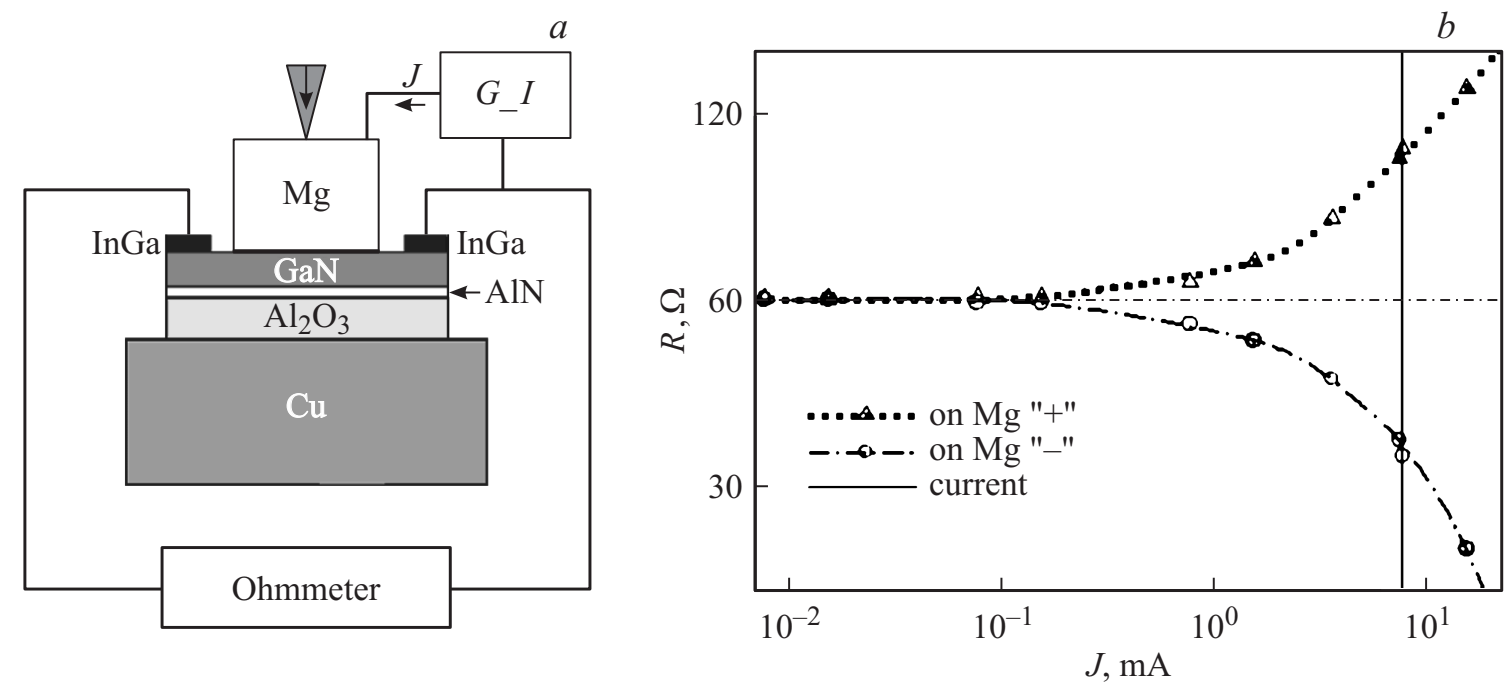

Рис. 2. $a$ - структура образца $\mathrm{GaN} / \mathrm{AlN} / \mathrm{Al}_{2} \mathrm{O}_{3}$ с Mg-контактом; $b-$ зависимость сопротивления пленки GaN от токов разной полярности через магниевый тесный контакт с пленкой (ток омметра $7.5 \mathrm{MA}$ ).

и совместить тепловой детектор и усилитель в одном кристалле. Но для надежной воспризводимости желательно использовать на пленке $\mathrm{GaN}$ затвор из $\mathrm{AlN}$ и на границе с магниевым электродом.

Созданные в лаборатории Жиляева на базе GaAs наиболее совершенные $p-i-n$-структуры [16] были использованы для построения микротермоэмиссионного преобразователя (рис. 4, $a$ ).

На приведенной в тепловой контакт микроструктуре на базе GaAs, так же как кремниевом $p-n$-переходе, был зарегистрирован смешанный фототермосигнал. За счет частичного поглощения излучения сильно легированным верхним слоем GaAs и его превращения в тепловой поток, зарегистрированный ранее на $p-n$-переходе на базе $\mathrm{Si}$, характерный резонанс также наблюдается и на $p-i-n$-переходе на базе GaAs (рис. 4,b). При этом резонанс максимальной амплитуды на $\mathrm{Si}$ наблюдается при полном поглощении никелем синего света. Тогда как более сильное, чем для синего света, поглощение ИК-излучения вблизи плазменного минимума GaN приводит к большему вкладу локальных термоэдс на ИКизлучение и характерный резонанс проявляется даже на ослабленном на 10 Дб, как и для $\mathrm{Si}$, излучении, но в ИК-диапазоне.

Таким образом, термоэлектрический „взгляд“ на $\mathrm{GaN}$ выявил ранее неучтенную физику: полуметаллический характер образца указывает на расщепление $s$-зоны $\mathrm{Ga}$ квази- $d$-зоной $\mathrm{N}$ и соответственно самолегирование $\mathrm{GaN}$. Также он выявил новые возможности применения GaN: 1) транзистор Лосева на барьере Шоттки на грани- 
$a$
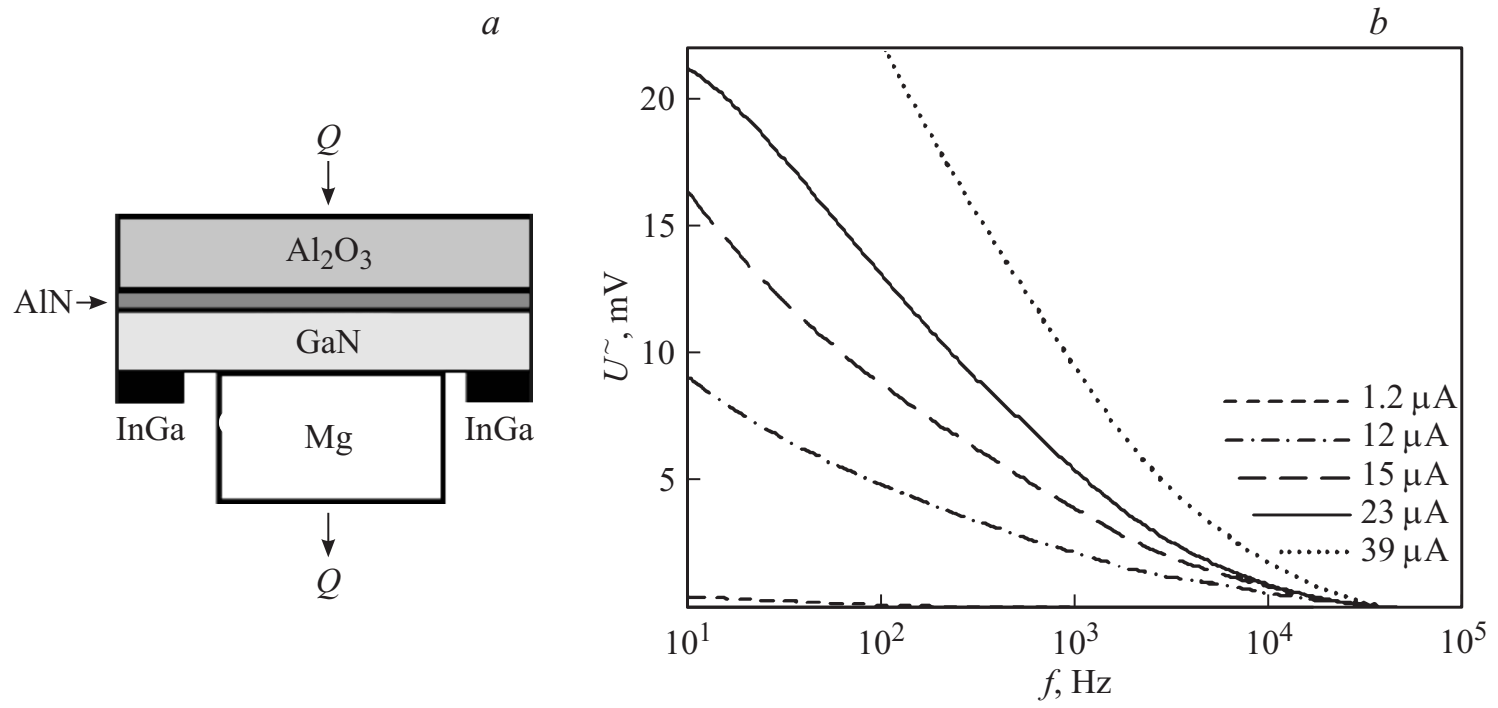

Рис. 3. Термотранзистор Лосева на базе $\mathrm{GaN}(a)$ и его входные частотные характеристики $(b)$.
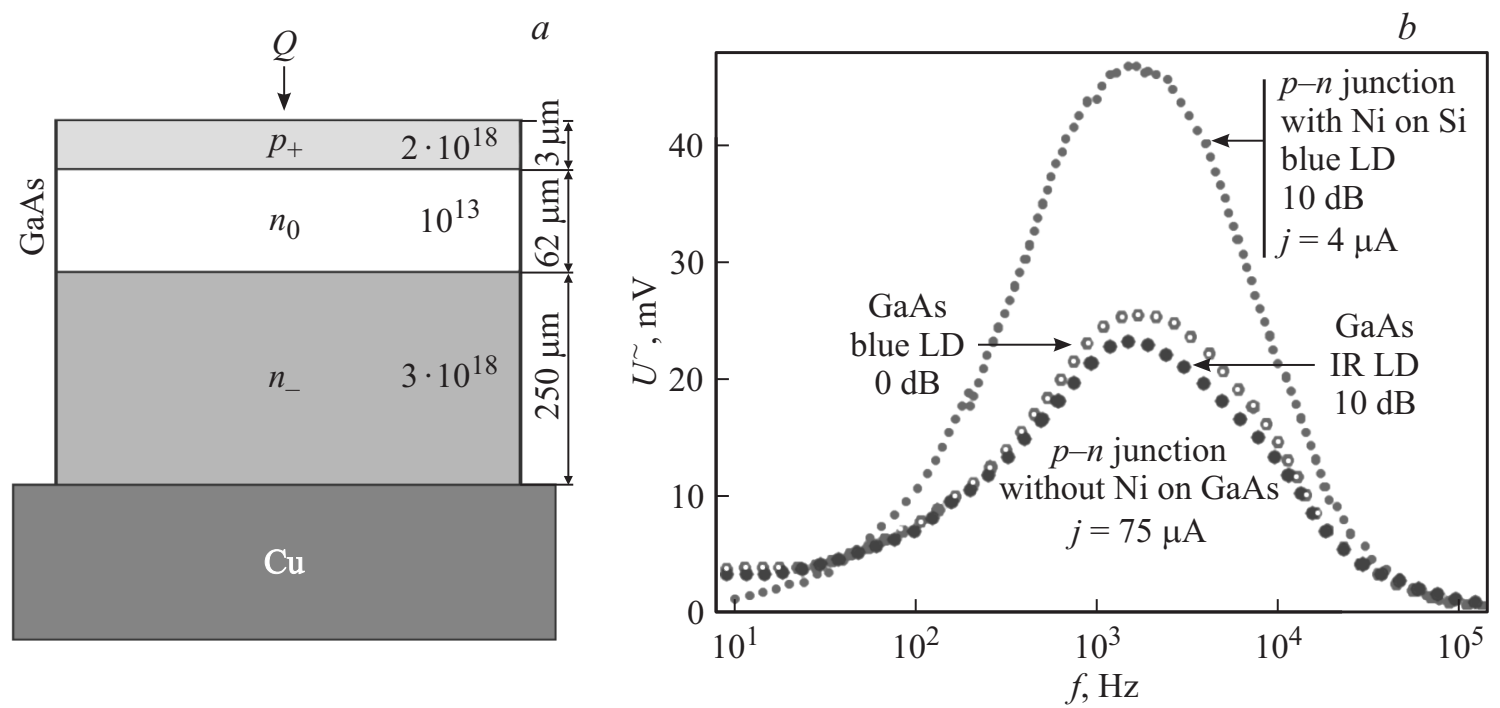

Рис. 4. $a$ - структура микротермоэмиссионного преобразователя; $b$ - гауссов резонанс, возникающий при оптимальном смещении $p-i-n$-перехода на базе GaAs, характерный при наличии локальных термоэдс.

це $\mathrm{Mg} / \mathrm{GaN} ; 2)$ термоэлектрический диод и термоэлектрический транзистор Лосева; 3) электрический контакт, прозрачный в видимой области спектра и в ближнем ИК-диапазоне; 4) широкополосный ИК-источник излучения (по патенту [16]). По результатам исследования структуры на базе GaAs показана принципиальная возможность использовать $p-n$-переходы на базе GaAs как для развития физики локальных термоэдс, так и для конструирования высокоэффективных устройств на базе локальных термоэдс, в частности, для создания чувствительных детекторов, работающих, в отличие от фотодетекторов, в широком спектральном диапазоне.

Общий вывод: в структурах на базе широкозонных полупроводников даже без экранирующего металлического покрытия локальные термоэдс дают значитель- ный, превосходящий наблюдаемый на неметаллизированных кремниевых $p-n$-переходах, вклад в суммарный фототермосигнал. Для достижения максимального кпд термоэлектрического преобразования в структурах на базе $\mathrm{GaN}$ и GaAs требуется оптимизация концентрации носителей в слоях и оптимизация толщин слоев.

\section{Список литературы}

[1] Л.С. Стильбанс. Термоэлектрические явления. Полупроводники в науке и технике (М.-Л., изд-во АН СССР, 1957) т. 1 , c. 113.

[2] Я. Тауц. Фото- и термоэлектрические явления в полупроводниках (М., ИЛИ, 1962). 
[3] CRC Handbook of Thermoelectrics, ed. by D.M. Rowe (N.Y., CRC Press, 1994).

[4] С.В. Ордин, И.А. Соколов, А.Ю. Зюзин. Тр. Междунар. конф. „Термоэлектрики и их применения““ (СПб., Россия, 2006) c. 41.

[5] С.В. Ордин, Н.В. Ванг. Тр. Междунар. конф. „Термоэлектрики и их применения“ (СПб., Россия, 2008) с. 55.

[6] S.V. Ordin, N.W. Wang. Adv. Energy Res., 9, 311 (2012).

[7] С.В. Ордин. ФТП, 31, 1091 (1997).

[8] С.В. Ордин. Тр. V межгос. сем. „Материалы для термоэлектрических преобразователей“ (СПб., Россия, 1997) c. 149.

[9] S.V. Ordin, A.Yu. Zjuzin, Yu.V. Ivanov, S. Yamaguchi. ITC2010, Shanghai, China, July, 2010 (J. Electron. Mater., 2010) p. 137.

[10] С.В. Ордин. Тр. Междунар. конф. „Термоэлектрики и их применения“ (СПб., Россия, 2014) с. 199.

[11] С.В. Ордин. Тр. XIV Междунар. конф. „Термоэлектрики и их применения“ (СПб., Россия, 2014) с. 234.

[12] С.В. Ордин и др. Тез. докл. науч.-практ. конф. „Современные тенденции и принципы построения оптикоэлектронных систем“ (Ростехнологии, УОМЗ, Россия, 2012) c. 62.

[13] Yu.V. Zhilyaev, S.N. Rodin. Tech. Phys. Lett., 36, 397 (2010).

[14] Yu.V. Zhilyaev, V.V. Zelenin, T.A. Orlova, V.N. Panteleev, N.K. Poletaev, S.N. Rodin, S.A. Snytkina. Tech. Phys. Lett., 41, 476 (2015).

[15] Yu.V. Zhilyaev, D.I. Mikulik, A.V. Nasonov, T.A. Orlova, V.N. Panteleev, N.K. Poletaev, L.M. Fedorov, M.P. Shcheglov. Tech. Phys. Lett., 38, 399 (2012).

[16] С.В. Ордин, А.И. Сомсиков. А.c. SU № 1434922 (1 июля 1988 г.).

Редактор А.Н. Смирнов

\section{Local thermoelectric effects in wide-gap semiconductors}

\section{S.V. Ordin, Yu.V. Zhilyaev, V.V. Zelenin, V.N. Panteleev}

loffe Institute,

194021 St. Petersburg, Russia

Abstract In structures on the basis of wide-gap semiconductors the experimental confirmation of emergence of local thermoelectromotive force, found earlier on silicon $p-n$-junctions, is obtained. Current-voltage and frequency characteristics of asymmetrical potential barrier at the $\mathrm{GaN} / \mathrm{Mg}$ interface, and $p-i-n$-structure based on GaAs have been investigated. It is shown that, similarly to wide-gap semiconductors, the contribution of the local thermoelectromotive force determines the current-voltage characteristics and the frequency characteristics of the current-watt performance, in particular Gaussian resonance. The proper account and use of local thermos-electromotive force allowed for cardinal increase in the efficiency of thermoelectric conversion and improvement of the operating parameters of microelectronic elements. 